\title{
As dimensões da construção social do patrimônio no Museu Vivo do São Bento
}

\author{
The dimensions of the social construction of heritage in the Museu Vivo do São Bento
}

Tatiane Oliveira de Assumpção Cordeiro*

Palavras-chave:

Patrimônio

Memória

Museologia Social

Keywords:

Heritage

Memory

Social Museology
Resumo: O presente artigo pretende apresentar as dimensões da construção social do patrimônio no âmbito de uma instituição que trabalha com a memória, com a história e com o patrimônio da região da qual se insere, a Baixada Fluminense, no estado do Rio de Janeiro. O trabalho traz a experiência do Museu Vivo do São Bento. Uma rica e inovadora experiência, sob o viés da museologia social, que atribui ao Museu o papel de agente com função social a partir de práticas que respeitem a diversidade cultural e integrem, de fato, a comunidade local. Desde a oficialização da sua criação, em 2008, através da reivindicação dos profissionais da área da educação do município de Duque de Caxias, no Estado do Rio de Janeiro, o Museu se constitui como um espaço de luta e resistência, e seus atores sociais buscam que essa instituição tenha ampla inserção entre os diferentes grupos sociais da Baixada Fluminense. E, através da perspectiva da educação patrimonial, inscrevem um processo importante de experimentação da própria perspectiva do patrimônio cultural. Essa experimentação é apreendida por meio de atividades, projetos/programas, além de sua própria inserção enquanto agente social, político, educacional e cultural.

Abstract: This article intends to present the dimensions of the social construction of the heritage in the institution that works with the memory, the history and the patrimony of the region of which the Baixada Fluminense is inserted, in the state of Rio de Janeiro. The work brings, therefore, the Museu Vivo do São Bento's experience. A rich and new experience, under the bias of social museology, which attributes to the Museum the role of an agent with a social function based on practices that respect cultural diversity and, in fact, integrate the local community. Since the creation in 2008 through the demand of education professionals in the municipality of Duque de Caxias, in the State of Rio de Janeiro, the Museum is a space of struggle and resistance and its social actors seek that the same has wide insertion among the different social groups of the Baixada Fluminense. And, through the use of the heritage education perspective, they sign up an important process of experimenting with the perspective of cultural heritage itself. This experimentation is apprehended through activities, projects/programs, as well as their own insertion as a social, political, educational and cultural agent.

Recebido em 02 de abril de 2019. Aprovado em 15 de julho de 2019.

\section{Considerações iniciais}

O presente artigo pretende apresentar as dimensões da construção social do patrimônio no âmbito do Museu Vivo do São Bento, uma instituição que trabalha com a memória, com a história e com o patrimônio da região da qual se insere, a Baixada Fluminense, no Estado do Rio de Janeiro. Este artigo deriva da minha pesquisa de mestrado, cuja dissertação é intitulada "'Seu lugar é no Museu!' A atuação do Museu Vivo do São Bento na construção de sentidos sobre o patrimônio da Baixada Fluminense". ${ }^{1}$ Desmitificar a região da Baixada Fluminense, colocar em pauta

\footnotetext{
* Licenciada em História pela Universidade Federal Rural do Rio de Janeiro (UFRRJ); Mestra em Patrimônio, Cultura e Sociedade, pelo Programa de Pós-Graduação em Patrimônio, Cultura e Sociedade da UFRRJ. E-mail: <oliveiratati93@gmail.com>.
} 
a perspectiva patrimonial com outras e novas formas de ver e dar a ver o patrimônio cultural da região, foi um movimento fundamental para a própria consolidação do trabalho do Museu Vivo do São Bento em torno da difusão de elementos identitários que são capazes de (re)inscrever às questões referente à cidadania nessa região tantas vezes marginalizada. As atividades propostas pelos membros APPH-CLIO não só revelaram ricas vivências e experiências como também acabaram contribuindo para difundir a perspectiva de que o patrimônio deve ser tomado como uma ferramenta de intervenção social e, ainda, como um importante mecanismo de construção de novas redes de solidariedade, de fraternidade, de identidade e de pertencimento. A história da criação do Museu Vivo do São Bento é marcada por lutas, mobilizações e resistências advindas dos professores do município de Duque de Caxias $^{2}$.A sensibilização em defesa do patrimônio propiciou o diálogo da comunidade local com o seu território e com o (re)conhecimento dos muitos "lugares de memória" presentes no cotidiano da Baixada Fluminense. Possibilitou, ainda, a essa população, por vezes excluída da dita História Oficial, experimentar e vivenciar a história através do patrimônio como meio de reflexão, mediação e intervenção social. Essa sensibilização contribui para que

[...] o patrimônio do território tornase um pretexto para refletir seriamente sobre o presente e sobre o futuro. E para se perguntar o que é possível fazer para avançar todos juntos, graças a esse laço que o patrimônio constitui para cada um. (VARINE, 2013, p. 187).

O Museu Vivo do São Bento constitui-se como uma ferramenta de luta por direitos, tendo em vista a valorização da vida, das relações sociais, das redes de pertencimento e da transformação social. Nesse sentido, busca incentivar as potencialidades do território, pois:

Se o museu tradicional delimita e elabora uma seleção de produções do homem, com o objetivo de fazer um recorte da realidade e encená-lo em um espaço definido, o museu de território procura a potencialidade do espaço, com o fim de trabalhar de forma integral a memória e a produção do patrimônio de forma dinâmica em sua complexidade. Esta forma de museu não estaria ligada ao passado, como coisa acabada, pois o museu pode ser tudo. (VIANA, 2009, p. 18).

O Museu Vivo do São Bento busca, desde sua constituição, essa potencialidade do espaço que se desdobra na própria percepção dinâmica que se pode ter do Museu em diálogo com outros elementos que se projetam no jogo das relações sociais como a memória e o patrimônio. O Museu integra, mediante um diálogo com a museologia, com a cultura e com a educação, uma perspectiva de (re)conhecimento, apropriação, conservação e valoração do patrimônio cultural.

Diante desses ideais, esse não poderia ser mais um museu dito tradicional. Por isso, o Museu Vivo do São Bento é idealizado e criado sob a ótica do contexto dos movimentos de renovação da museologia, a museologia social. A museologia social tem como propósito viabilizar estratégias que permitam que os museus assumam um novo papel no que tange ao aspecto museológico: lidar não apenas com o seu acervo, com objetos e exposições, mas sim, com o aspecto humano, isto é, lidar com as pessoas, com o território, com o desenvolvimento local, com o patrimônio, com a memória. Enfim, essa nova perspectiva de se fazer museologia assume o papel de lidar e lutar pela vida, pois, "o museu era - ou antes, deveria ser - um instrumento a serviço do desenvolvimento" (VARINE, 2013, p. 171). Nesse viés, essa perspectiva museológica proporciona englobar grupos, comunidades, lugares, patrimônios, memórias, antes não vistos, não ouvidos e não lembrados, rompendo barreiras, quebrando paradigmas e buscando superar as fraquezas/falhas/lacunas deixadas pela museologia tradicional.

A museologia social também compreende que o patrimônio é mutável e está sempre em movimento em suas mais variadas dimensões e possibilidades. Há de se considerar que, nessa perspectiva, os atores sociais do Museu Vivo do São Bento fazem desse um Museu em movimento; este 
e a comunidade escrevem, tecem histórias, relações, identidades e pertencimento.

\section{Novos olhares e novas vozes ao patrimônio cultural: a experiência do Museu Vivo do São Bento}

O Museu Vivo do São Bento atua de forma combativa e participativa no município de Duque de Caxias, na Baixada Fluminense. As demandas da sociedade local são as pautas principais do Museu que, inclusive, se entende como uma ferramenta a ser apropriada pela população como forma de resistência, mobilização, conhecimento e desenvolvimento. Cabe destacar que o bairro do Grande São Bento, que se constituiu como espaço expressivo do museu, é um território pobre, carente de saneamento, moradia, educação, direitos básicos e essenciais aos cidadãos. É uma realidade dura e árdua.

A luta e a mobilização em busca de melhorias da qualidade de vida encontram-se entrelaçadas à luta em defesa do patrimônio cultural, como realça o trecho a seguir destacado, oriundo da entrevista realizada com a Marlúcia de Souza, articuladora e diretora do Museu Vivo do São Bento, presente na tese do Uhelinton Viana:

Estávamos um tempo aqui nessa comunidade, mas a carência aqui é muito grande de tudo. Uma das lutas das mães aqui é a creche. Quando elas viram o prédio sendo reformado, pensaram na necessidade delas, que era a creche. E que era justa, mas achávamos que a luta em defesa do patrimônio não precisava ser excluída para manter a outra. Daí começamos a articular a luta pela creche. (VIANA, 2016, p. 195).

Aqui não tem como, esse território do grande São Bento abrange uma das regiões mais pobres da cidade. Tem ocupações na beira do Rio Sarapuí e mais que quinze mil pessoas em situação de precariedade em favelas. Uma situação sem infraestrutura e uma população extremamente pobre. Por conta disso, aqui não podemos ter um museu, por exemplo, mostrando a coroa do imperador e dando as costas para a comunidade. Se você quiser fazer uma defesa pelo patrimônio local, você tem que interagir com outras demandas das lutas sociais. Porque não podemos dar as costas para aquela mulher que trabalha e não tem creche para seu filho. Mas, ao mesmo tempo, nosso trabalho é mostrar à comunidade que esse espaço é dela e que ela pode transformar este espaço em um espaço de reunião, de organização de suas lutas, mas, também, de preservar os seus guardados, sua herança, seu patrimônio. (VIANA, 2016, p. 196).

Suas atividades e ações nos mostram que o Museu atua em defesa do patrimônio cultural, das relações sociais, da vida em sociedade, na luta por direitos sociais básicos, contra as desigualdades sociais, a intolerância religiosa e os preconceitos étnico-raciais. Essas questões fazem parte da militância dos professores que atuam e colaboram no Museu e, por conseguinte, são preocupações presentes antes mesmo de sua criação. Convém sublinhar que:
A luta pelo Museu e pelo patrimônio não é isolada, está articulada às lutas das comunidades por moradia, saneamento, luz, educação. O Museu não está deslocado no bairro São Bento, mas a serviço das comunidades e tem como proposta integrar a comunidade não somente na questão das memórias e do patrimônio, mas aos problemas da localidade. O Museu se faz na comunidade e se produz a partir de sua realidade e não sobre ela. Reivindica com a comunidade, com as Associações de Amigos do Museu, sindicalistas etc.; e cobra do poder público condições dignas para as camadas desfavorecidas das populações que habitam e circulam pelas adjacências. (VIANA, 2016, p. 192).

A criação do Museu reafirmou a necessidade de debater tais pontos; assim, ele se tornou, pouco a pouco, um expressivo "lugar de fala" dos moradores do bairro. Isso se torna perceptível e está muito presente e vivo nas ações, nas exposições, nas pesquisas, nos projetos/programas e nos cursos desenvolvidos pelo Museu. A exposição "Mulheres 
em Movimento na Cidade de Duque de Caxias", a pesquisa "Tempo da Conquista Lusitana" e o seminário "Patrimônio: sentidos e conflitos na cidade de Duque de Caxias" são alguns desses exemplos. Exemplos que nos trazem as vivências, as experiências bem como os saberes e fazeres da gente dessa localidade tão estigmatizada; exemplos que nos mostram a riqueza da cultura brasileira em sua pluralidade, e tecem novas perspectivas identitárias sobre a própria Baixada Fluminense.

A exposição itinerante "Mulheres em Movimento na Cidade de Duque de Caxias", por exemplo, traz a trajetória de quinze mulheres militantes que ocuparam espaços e tiveram importante inserção social na luta por direitos e que enfrentaram e se mobilizaram contra as desigualdades e injustiças sociais. Essa exposição torna pública a história e a memória dessas mulheres que viveram e atuaram na cidade de Duque de Caxias e que deixaram um importante legado de luta e resistência.

A pesquisa "Tempo da Conquista Lusitana" desenvolvida em parceria com o Centro de Referência Patrimonial e Histórico do Município de Duque de Caxias (CRPH) desperta na população, por sua vez, o interesse em conhecer a história da região ao fomentar o conhecimento sobre o território da antiga Fazenda do Iguaçu e das Cercanias da Guanabara no século XVI. Compreende-se que:

[...] o Museu Vivo do São Bento tem procurado contribuir para o conhecimento da história da local seja da região do Grande São Bento, do município de Duque de Caxias ou mesmo da Baixada Fluminense -, trazendo à memória a história tanto das pessoas que viveram nessas localidades em outras épocas como a das que vivem no presente. Ao expor essas histórias, valoriza-se o protagonismo dos sujeitos comuns - aqueles que não têm visibilidade social e, por isto, passam anonimamente pela história oficial - e revela-se uma outra história. (GOMES, 2016, p. 56).

É interessante mencionar, ainda, o seminário "Patrimônio: sentidos e conflitos na cidade de Duque de Caxias", realizado em 2016, na sede administrativa do Museu, que se voltou para o debate sobre políticas públicas e ações coletivas no campo patrimonial e tratou das temáticas "Patrimônio em um mundo de propriedades", "Patrimônio e Museologia social: o Museu Vivo do São Bento em foco", "A vida como patrimônio" e "Patrimônio, África e Cultura Afro Brasileira". Esses temas são bastante significativos, pois se inscrevem dentro da perspectiva ampliada e democrática de patrimônio cultural e museologia, além de serem importantes para a constituição de redes de solidariedades a partir de vivências e experiências no âmbito das demandas e preocupações da população local.

Tais práticas, ao serem compartilhadas, criam mecanismos de sensibilização que agem no sentido de integrar a sociedade e, ainda, inserem-se em um processo mais amplo e plural, pois, tornamse práticas políticas já que integram questões como a dignidade e a justiça social. Além disso, contribuem para a constituição de uma relação afetiva com o lugar, de reconhecimento com os "lugares de memória", que ao englobarem a memória, a história e o patrimônio, integram também o afeto, o sentimento, a sensibilidade para a vida. Além disso, essas práticas também demonstram a importância do fomento e constituição de políticas de resistências e lutas pelo patrimônio capazes de transformar vidas.

A percepção do alcance e do sentido mais amplo da prática museológica do Museu Vivo do São Bento é fundamental. Compreender que museus têm função social é compreendê-los como pertencentes a uma museologia de prática libertadora e que contribui para a construção da dignidade humana. A museologia social enfrenta desafios complexos, pois, em sua essência, preocupase com o desenvolvimento local, com o território do qual está inserido e, mais que isso, preocupa-se com a vida, com a população do seu entorno. Entende-se que "[...] lidar com pessoas é muito mais complexo do que lidar com objetos, mas esse é o desafio dos museus que buscam o caminho das relações e das convivências humanas" (CHAGAS, 2002, p. 33). Esse é um desafio que se percebe nas atividades referenciadas neste artigo, inscritas e difundidas a partir do espaço do Museu na região do São Bento em Duque de Caxias. 
Lidar com pessoas é perceber que os museus são feitos por vidas e, por isso, não são e não podem ser abstratos, isolados da sociedade. Os museus devem ser concebidos e entendidos como espaço de luta, de reivindicação e, sobretudo, como um espaço de relações criativas. Esses espaços devem ser ocupados pela população como meio de mobilizar e intervir na realidade sociocultural. Como é o Museu Vivo do São Bento: nasce do movimento. É um movimento... E, assim como a vida, está sempre em movimento. É interessante observar que "[...] o Museu Vivo do São Bento está em permanente processo de construção, não está acabado e pronto, mas se faz e acontece nas lutas e com a comunidade" (VIANA, 2016, p. 199).

Como exposto anteriormente, no Museu Vivo do São Bento, os espaços são ocupados e apropriados pela população por intermédio também dos seus programas/projetos. Merecem realce, em virtude de seu alcance social, os projetos "Mulheres Artesãs" e "Jovens Agentes do Patrimônio". Tais programas/projetos têm como intuito favorecer as trocas culturais e patrimoniais além de promover a constituição de iniciativas análogas em outras áreas do município e incentivar a produção artística cultural dos cidadãos da Baixada Fluminense, especialmente na região do São Bento. Contribuem para a construção de sentimentos de pertencimento e de coletividade, e incitam e convidam à experimentação da perspectiva da noção do patrimônio cultural.

O projeto "Mulheres Artesãs" é vivenciado por mulheres moradoras da comunidade local que trazem consigo saberes, sabores e experiências que, compartilhados com o coletivo, ganham forma e expressão por meio do artesanato e da culinária. $\mathrm{O}$ coletivo se reúne semanalmente, às quintas-feiras, $\mathrm{e}$ suas criações são divulgadas no espaço do Museu, em feiras e em eventos culturais. Suas artes também são vendidas, contribuindo para a renda das artesãs. Para os atores sociais do Museu "[...] através de múltiplas linguagens e sabores, numa ambiência afetiva e reflexiva, elas ensinam e aprendem, trocam e destrocam, acumulam e desapegam, insistem e desistem, experimentam a arte no mistério, nas conversas, nos desejos, na dúvida, nas diferenças, no coletivo" 3 .Nas vivências do Museu Vivo do São Bento, as mulheres que participam desse projeto materializam suas ideias através do artesanato e culinária, criam e recriam saberes e sabores, como nos conta Maria do Socorro, participante do Projeto Mulheres Artesãs. ${ }^{4}$

Faço todo tipo de artesanato, porque aqui é assim, o que uma faz, passa para outra. Aqui não tem professor, vem sim, sempre alguém que é convidado para passar a novidade pra gente, mas a gente, uma vai passando o que aprende para a outra. (SOCORRO, 2018).

Depreende-se, a partir da fala de Maria do Socorro, que essas mulheres se apropriam do Museu não apenas como um espaço de socialização, mas também como um espaço de trocas e experiências, como um meio de aprimorar seu saber-fazer, de sentir-se pertencente a um coletivo que fomenta e estimula os laços de pertencimento, a cidadania e as trocas culturais. Dessa forma, "[...] os encontros constituem-se em espaçotempo de tecer narrativas e memórias das comunidades e de troca de saberes" (VIANA, 2016, p. 223).

O projeto "Jovens Agentes do Patrimônio", por sua vez, contribui para que os jovens da comunidade local construam um referencial de valorização e preservação do patrimônio cultural mediante processos de experimentação da própria perspectiva patrimonial. Tais processos de experimentação do patrimônio são vivenciados por diálogos, reflexões e rodas de conversas para se construir o referencial de patrimônio coletivamente, através da atribuição de valor, identificação, reconhecimento e sentimento/afetividade. Além disso, o projeto estimula esses jovens a compreenderem museus e patrimônios como elementos fundamentais para o desenvolvimento local. Esses jovens, uma vez incitados a refletirem sobre o patrimônio, em sua dimensão mais viva, acabam descobrindo-se sujeitos ativos, pois,

[...] lembremo-nos mais uma vez que os jovens de hoje são os tomadores de decisão de amanhã. Eles devem, portanto, estar em plena posse de sua cultura viva e de suas heranças culturais 
e naturais para poder desempenhar seu papel de atores da comunidade e de seu desenvolvimento. (VARINE, 2013, p. 91).

Nos encontros, os jovens agentes do patrimônio, procuram pensar a perspectiva patrimonial a partir das suas referências, das suas realidades, do seu cotidiano. Fomenta-se um encontro com as perspectivas de patrimonialização, a preservação e valorização dos bens e das práticas culturais que são socialmente reconhecidos pela própria comunidade local. Essa ideia torna-se perceptível no conceito ${ }^{5}$ criado por esses próprios jovens. Para eles,

[...] patrimônio é o caminho das formigas [...] os botões que a Jacqueline achou enterrados ${ }^{6}$, é a tristeza e é a morte ${ }^{7}$, é a comunidade ${ }^{8}$. Todas as coisas ao nosso redor são patrimônio: o que é importante e o que parece não ser importante ${ }^{9}$, a conversa com a amiga, o dia-a-dia $[s i c]$, as pessoas, a vergonha. É um patrimônio saber que a gente é uma comunidade [...]. (CHAGAS, 2015, p. 179).

O conceito criado por esses jovens, muito bem abordado por Mario Chagas em seu texto "Patrimônio é o caminho das formigas..." ao trabalhar sobre os Jovens Agentes do Patrimônio, demonstra que a vida é o patrimônio. As práticas e as relações sociais e culturais são o patrimônio dessa comunidade que não precisa de um aval oficial para ser reconhecido como tal. Entender a perspectiva patrimonial por essa óptica é muito importante para que a concepção de patrimônio cultural seja democrática e contribua para a formação identitária e cidadã que ajude a romper paradigmas e estereótipos associados à região da Baixada Fluminense, por muitas vezes discriminada. Para a jovem Jacqueline de Oliveira, participante do projeto Jovens Agentes do Patrimônio ${ }^{10}$, as contribuições são fundamentais para a descoberta de sua própria história:

Tenho aprendido que eu preciso valorizar mais a minha história. Não só patrimônio material, mas imaterial; não só as coisas que a gente vê, tipo os monumentos, mas também as pessoas que têm história. (OLIVEIRA, 2018).

Ao incitar os frequentadores do Museu a experimentarem a perspectiva de patrimonialização de seus bens e suas práticas culturais entra em curso o exercício do "rememorar" que se desdobra na formação de redes de identificação e pertencimento. Associar o patrimônio cultural aos "lugares de memória" funciona como um mecanismo para revitalizar e potencializar a identidade e a memória coletiva local. Dessa forma,

[...] faz-se necessário o diálogo entre a sociedade, o significar e a identificação e salvaguarda do patrimônio, que deve ocorrer na sua formação enquanto memória coletiva e acima de tudo na formação dos mais diversificados lugares, capazes de traduzir o ser e sua contribuição temporal, espacial e simbólica para a nação, a sociedade e à própria cidade. (ANGELO, 2016, p. 18).

Nessa perspectiva, o Museu Vivo do São Bento apresenta resultados que podem ser presentificados no cotidiano já que a sociedade local passa a (re)conhecer a história regional, interagindo com o espaço museológico e promovendo trocas culturais nas festividades e eventos. Reafirmam-se e se difundem as tradições locais, já que é a comunidade quem integra as vivências do Museu. $\mathrm{O}$ mesmo ocorre com a experimentação da própria perspectiva de patrimônio cultural, já que, em museus ancorados na museologia social, é a sociedade que deve atribuir valor e significado aos bens e as práticas culturais, bem como, ter plena liberdade para apropriar-se destes, usá-los, conservá-los, conferirem significados e ressiginificá-los.

\section{Museu Vivo do São Bento: educação e afeto no patrimônio}

Como observado ao longo desse artigo, para os atores sociais do Museu Vivo do São Bento, o patrimônio e sua importância maior está no sentimento e na memória que ele abriga, que não engloba apenas valores econômicos, mas também e, 
principalmente, valores afetivos e simbólicos, como a noção de memória afetiva que consolida a noção de patrimônio no indivíduo, despertando vínculos que o levam a querer exercer sua cidadania.

Essa ideia é fundamental para que se tenha "uma ampliação do espectro daquilo que é visto como patrimônio" (NAJJAR, 2010, p. 142). É preciso que se incluam outros atores sociais para que assim a perspectiva patrimonial seja inclusiva e não excludente. Sendo o patrimônio um campo social e também político, há uma seleção para determinar o que se enquadra ou não como patrimônio. Como destaca Márcia Chuva:

[...] a patrimonialização de práticas culturais (ou de bens culturais de natureza imaterial) promove a concorrência e, por vezes, a dissensão entre grupos, vivenciada através de tensões e disputas, num contexto de lutas de representação, lutas por legitimidade e lutas políticas, que redundam em disputa por recursos direta ou indiretamente. (CHUVA, 2012, p. 74).

O Museu Vivo do São Bento idealizado e criado por professores e concebido sob a perspectiva da museologia social, valoriza e inscreve em suas atividades as perspectivas de socialização e sensibilização para o patrimônio que não poderiam se efetivar de outra maneira, senão pela educação. Pedagogia do afeto, memória do afeto e museologia do afeto estão presentes e são marcantes no Museu Vivo do São Bento. A cada atividade proposta, colocase em prática o exercício do estranhamento e de desnaturalização para vivenciar que museus têm em si um mundo de possibilidades e experiências, como nos conta a coordenadora do programa Jovens Agentes do Patrimônio, Risonete Nogueira ${ }^{11}$.

Sem dúvidas, o Museu Vivo do São Bento desempenha uma função educacional. De muitas maneiras, sendo um museu aqui no segundo distrito de Duque de Caxias, de um lugar onde muitas pessoas nunca tinham ouvido falar de um museu, do que era um museu. Mas principalmente na sua transfiguração do que seja museu, numa mentalidade que a gente já carrega há muitos anos, que a transfiguração de um lugar que era reservado para alguns para um lugar que deve ser construído por todos, por muitos e por todos. Então essa função educativa ela é muito grande, só na sua existência ela já se afirma e depois em tantos movimentos que se faz, na receptividade, nas trocas, nas experiências, na colhida de todo mundo, na nossa predisposição de estar em movimento por aí, por onde faz sentido estar. Então, tudo isso é função de educar. (NOGUEIRA, 2018).

Ao desempenhar sua função social, o Museu Vivo do São Bento também desempenha sua função educativa. É uma via de mão dupla. É a museologia e a educação como práticas da liberdade. É a educação e o museu como patrimônio a serem usados, compartilhados e transmitidos. No âmbito dessa discussão, Marlúcia de Souza ${ }^{12}$, articuladora e diretora do Museu, nos fala da importância de se trabalhar a educação patrimonial também como forma de reconhecimento da história local:Temos muito trabalho pela frente... Limitados pela escassez, na medida do possível, por exemplo, hoje você faz um concurso para Duque de Caxias tá lá sambaqui, tá lá a história da cidade, ninguém sabia o que era antes.

Nós acreditamos que a educação
patrimonial ela tá em tudo, está no
trabalho de campo que eu faço... Tudo,
tudo é educação para a vida, patrimônio
edificado, histórico, ambiental,
arqueológico... É o conceito dos jovens
'patrimônio éo caminho das formigas, éa
vida, o cotidiano', esse é o trabalho que a
gente faz, poderia ser mais potente, temos
que fazer mea culpa... Mas os ataques
vêm de tantos lados que, às vezes, não
temos reação imediata, é muita coisa pra
dar conta. (SOUZA, 2018).

Essa perspectiva educacional passou a ser denominada e conhecida por muitos como educação patrimonial. Atrelam-se práticas educativas tendo como foco o diálogo com o patrimônio cultural e trabalha-se com o desenvolvimento e o estímulo à memória, a cidadania, a identidade. 
O seu vínculo de fundo e o seu diferencial estão situados na confluência entre a educação, a memória, a cultura, o patrimônio e a preservação. De outro modo: a expressão em análise constitui um campo e uma prática de educação socialmente adjetivada e não está especialmente vinculada a nenhuma metodologia, a nenhum autor, a nenhum lugar, a nenhuma data em particular. (CHAGAS, 2013, p. 5).

A expressão “educação patrimonial” nada mais é do que educação. Isso ressalta a importância de desenvolver a perspectiva de trabalhar a educação como patrimônio, pois, da mesma forma que o patrimônio, a educação também é uma prática sociocultural; então:

É que se pode falar no caráter indissociável da educação e da cultura ou ainda na inseparabilidade entre educação e patrimônio. Não há hipótese de se pensar e de se praticar a educação fora do campo do patrimônio ou pelo menos de um determinado entendimento de patrimônio. Por este prisma, a expressão "educação patrimonial” constituiria uma redundância ${ }^{13}$, seria o mesmo que falar em "educação educacional" ou "educação cultural”. No entanto, não se pode negar que a referida expressão tenha caído no gosto popular. Resta, nesse caso, compreender os seus usos e os seus significados. (CHAGAS, 2013, p. 4).

A inscrição da educação, noâmbito do Museu Vivo do São Bento, contribui para a constituição de mecanismos que estimulem a produção de sentidos e ensinem que há um direito à memória, à história, à museologia e ao patrimônio. Como nos incita a refletir Risonete ${ }^{14}$, a educação é um referencial que está para muito além do espaço formal escolar. Ela é ampla e dialoga com a perspectiva patrimonial e as memórias mais profundas e afetivas que dão sentido à vida dos homens e das mulheres:

Eu fui agregando olhares e possibilidades de enxergar esse lugar $e$ de estar nesse lugar que é a escola, não é a educação, mas a escola, porque a educação para mim é uma coisa muito mais ampla que a escola deveria agregar. E que eu acho que tem tudo a ver com o patrimônio, patrimônio para mim está relacionado ao afeto, educação sem afeto, para mim, não existe. Os afetos eles redimensionando sempre e continuam redimensionando o que eu aprendo, o que eu desaprendo, é o que vai determinar. E o que a gente aprende e tem a possibilidade de desaprender para mim se constitui o maior patrimônio, porque não é fixado, é nessa abertura que eu entendo o conceito de patrimônio. (NOGUEIRA, 2018).

O Museu Vivo do São Bento atua, para tanto, na tênue fronteira que se estabelece entre a experimentação do patrimônio cultural e da sua função educativa, no viés da museologia social. É interessante observar que

[...] a educação patrimonial constituise de todos os processos educativos formais e não formais que têm como foco principal o patrimônio cultural, apropriado socialmente como recurso para a compreensão sócio-histórica das referências culturais em todas as suas manifestações, a fim de colaborar para seu reconhecimento, valorização e preservação. (IPHAN, 2014, p. 19).

É, por esse viés também, que os programas e os projetos do Museu são importantes, visto que eles se inscrevem dentro da perspectiva daquilo que seria a patrimonialização das práticas culturais. Além disso, proporcionam pensar e, principalmente, combinar, em uma rica tessitura, novas possibilidades de formação identitária a partir das memórias e identidades individuais que, ao serem (com)partilhadas, se tornam coletivas, como ressalta Pierre Nora (2009, p. 9):

[...] a ideia de que são os coletivos que têm uma memória implica numa profunda transformação do lugar dos indivíduos na sociedade e de sua relação com o coletivo; é lá que está o segredo, por trás da emergência misteriosa de algo mais: a identidade.

Nesse viés, é fundamental conceber a educação - entendida aqui como patrimônio e como 
forma de aproximação com o patrimônio - como um direito e um dever de todos, como um instrumento de conhecimento, cidadania, cultura e resistência, de criatividade, de trocas e de desenvolvimento e, principalmente, como uma prática social aberta ao exercício do novo. De tal maneira:

[...] seu objetivo é claramente o desenvolvimento local e, não uma mera aquisição de conhecimentos sobre o patrimônio, ou uma animação cultural. A proposta visa a levar o maior número possível de membros da comunidade a conhecer, a dominar e a utilizar o patrimônio comum dessa comunidade. (VARINE, 2013, p. 137).

As ações do Museu Vivo do São Bento em torno do estímulo ao sentimento de pertencimento e sua apropriação e vivência pela sociedade civil permite a (re)inscrição dos processos de patrimonialização de práticas culturais que envolvem os grupos da Baixada Fluminense. Essas singularidades estão fortemente marcadas nas memórias individuais e precisam ser reconhecidas e socializadas para não ficarem no esquecimento. A atuação do Museu Vivo do São Bento vincula-se, dessa forma, a esse sentido da memória e da própria reconstrução dos "lugares de memória." Como salienta Nora (1993, p. 13):

[...] os lugares de memória nascem e vivem do sentimento que não há memória espontânea, que é preciso criar arquivos, que é preciso manter aniversários, organizar celebrações, pronunciar elogias fúnebres, notariar atas, porque essas operações não são naturais. É por isso a defesa, pelas minorias, de uma memória refugiada sobre focos privilegiados e enciumadamente guardados nada mais faz do que levar à incandescência a verdade de todos os lugares de memória. Sem vigilância comemorativa, a história depressa os varreria.

O Museu Vivo do São Bento articula em seus programas e projetos novos caminhos para se pensar o patrimônio cultural e integra a experimentação do patrimônio em suas diferentes perspectivas, inscrevendo-o como algo natural e cultural, material e imaterial, e ainda como a própria história e a memória, pois acredita que:

[...] o patrimônio (natural, cultural, vivo ou sacralizado) é um recurso local que só encontra sua razão de ser em sua integração nas dinâmicas de desenvolvimento. Ele é herdado, transformado, produzido e transmitido de geração em geração. Ele pertence ao futuro. (VARINE, 2013, p. 21).

Observa-se que as atividades e ações do Museu Vivo do São Bento promovem conhecimento, reconhecimento e identificação com elementos do cotidiano que passam a ser apreendidos e vivenciados como referências e práticas culturais e patrimoniais. De tal forma, é fundamental pensar museus, patrimônio e educação em perspectivas críticas, para se tornarem ferramentas participativas.

\section{Considerações finais}

Para além de compreender que museus e patrimônios não se restringem ao fato de serem para a comunidade, pois isso já está dado desde o momento em que são vistos como construções sociais, é necessário compreender e desenvolver que museus e patrimônios estão com a comunidade. Esse entendimento leva a uma construção inclusiva e participativa e faz com que a museologia social e o patrimônio cultural sejam ferramentas, de fato, democráticas.

Nesse viés, as práticas culturais da sociedade civil da Baixada Fluminense em articulação com as atividades do Museu Vivo do São Bento viabilizam a apreensão de como essa instituição inscreve a noção de patrimônio, que tem como pauta não a sua materialidade ou tangibilidade, mas sim o sentido, o valor, o significado e o afeto atribuídos, já que no âmbito do Museu o patrimônio se afirma e reafirma no cotidiano.

As dimensões da construção social do patrimônio no Museu Vivo do São Bento passam pela educação, pela museologia, pela memória, pelo afeto, pelo pertencimento e pela própria perspectiva de patrimônio. Dimensões simbólicas, permeadas de 
subjetividades, a partir das quais se experimentam e se vivenciam sensações, interpretações, sentimentos e sentidos em um constante processo de criação e reinvenção, de atuação corajosa e apaixonante e de ações criativas, criadoras e transformadoras.

Tendo em vista a concepção de que patrimônio é algo dinâmico, integrar as perspectivas de museu, educação, sociedade e território é fazer viver o patrimônio. Nessa percepção, compreendese que o Museu Vivo do São Bento ao desenvolver tais interações, torna-se um espaço de múltiplas possibilidades. Possibilidades que são apreendidas pela comunidade a partir das vivências, experiências e sentidos das ações do museu.

O sentido, o papel e a importância do patrimônio cultural e seus desdobramentos no jogo das relações sociais possibilita compreender o valor simbólico de um bem ou uma prática cultural e, ainda, nos ajuda a perceber como o mesmo pode vir a ser apropriado pelos grupos de diferentes formas. Essa perspectiva patrimonial mais abrangente fomenta a construção de lugares de sentidos e, ao mesmo tempo, estimula o fortalecimento da construção identitária, de valorização do lugar e do exercício da cidadania.

É desta maneira que o Museu Vivo do São Bento é construído: por todos e para todos. Ao ser apropriado pela comunidade também como uma ferramenta de luta, constroem-se laços de solidariedade e fraternidade e se incentiva que o Museu ocupe lugar social e político para aqueles que o vivenciam. Os conflitos sociais tão presentes no território, a luta por direitos básicos como educação, saúde e saneamento, e a luta em defesa da valorização da vida ecoam no Museu e fazem dele ser um espaço de reivindicação em prol da garantia do cumprimento dos direitos da comunidade e do território. Essa mobilização social faz o Museu Vivo do São Bento ter vida e sentido.

\section{Notas}

1 A pesquisa de mestrado foi desenvolvida no Programa de Pós-Graduação em Patrimônio, Cultura e Sociedade (PPGPACS) da UFRRJ, sob orientação da Profa Dra Raquel Alvitos. A dissertação foi apresentada em fevereiro de 2019.

2 A APPH-CLIO é a Associação de Professores e Pesquisadores da História, formada por professores da rede pública e sindicato e os professores do Departamento de História da Faculdade de Filosofia, Ciências e Letras de Duque de Caxias que se articularam, nos anos 90, no século XX, para iniciar pesquisa sobre a história local e, assim, difundir a História da Baixada Fluminense, na luta pelo direito à memória, à história e ao patrimônio.

3 Retirado do site do Museu Vivo do São Bento, disponível em: http://www.museuvivodosaobento.com. br/projetos/mulheres-artesas. Acesso em: 26 mar. 2018.

4 Entrevista de Maria do Socorro concedida a Tatiane Oliveira de Assumpção Cordeiro, realizada no dia 18 de outubro de 2018 na sede administrativa do Museu Vivo do São Bento.

5 Esse conceito criado coletivamente pelos jovens, como destaca Mario Chagas (2015), tem uma dimensão poética de Manuel de Barros ("é no ínfimo que vejo a exuberância"). $\mathrm{O}$ caminho das formigas atravessa a dimensão natural e cultural e possibilita o repensar de outros e novos caminhos a serem (re)descobertos.

6 A referência textual pode ser vista também como uma analogia aos Sambaquis. O Sambaqui do São Bento é sítio arqueológico na região, que guarda os vestígios das ocupações humanas pré-cabralinas nas cercanias da Guanabara, destinado à instalação do Museu dos Povos das Conchas.

7Trata-se de referência aos exemplos de patrimonialização ancorados na dor, tristeza e morte, como as cidades de Pompéia e Herculano, na atual Itália, destruídas pelo Vulcão Vesúvio. (CHAGAS, 2015).

8 Ressalta-se que, na perspectiva dos jovens participantes do projeto, a noção de pertencimento à comunidade $\mathrm{e}$ as relações sociais também constituem a noção de patrimônio.

9 Convém destacar que, para os atores sociais do Museu Vivo do São Bento, o patrimônio não está restrito apenas àqueles reconhecidos em caráter oficial seja pelo IPHAN, seja pelo INEPAC, por exemplo.

10 Entrevista de Jacqueline de Oliveira concedida a Tatiane Oliveira de Assumpção Cordeiro, realizada no dia 25 de outubro de 2018 na sede administrativa do Museu Vivo do São Bento.

11 Entrevista de Risonete Nogueira concedida a Tatiane Oliveira de Assumpção Cordeiro,, realizada no dia 25 de outubro de 2018 na sede administrativa do Museu Vivo do São Bento.

12 Entrevista de Marlúcia de Souza concedida a Tatiane Oliveira de Assumpção Cordeiro realizada no dia 25 de outubro de 2018 na sede administrativa do Museu Vivo do São Bento.

13 Ainda que o uso da referida expressão possa configurar em uma redundância, dado a sua naturalização e recorrente utilização, ao longo do texto poderá ser feito uso da mesma. 
14 Entrevista de Risonete Nogueira concedida a Tatiane Oliveira de Assumpção Cordeiro realizada no dia 25 de outubro de 2018 na sede administrativa do Museu Vivo do São Bento.

\section{Referências}

ANGELO, Elis Regina Barbosa. Os caminhos do processo de formação do patrimônio cultural: Ideais e perspectivas contemporâneas sobre a educação para a memória e o pertencimento. In: ANGELO, Elis Regina Barbosa; SIQUEIRA, Euler David (Org.). Concepções, Memória e Patrimônio Cultural. História, Sociedade e Educação em foco. Curitiba: Editora Prismas, 2016. p. 15-28

CHAGAS, Mario de Souza. Museu, literatura e a emoção de lidar. Cadernos de Sociomuseologia, $n$. 19, p. 5-41, 2002.

CHAGAS, Mario de Souza Educação, museu e patrimônio: tensão, devoração e adjetivação. In: TOLENTINO, Átila Bezerra (Org.). Educação Patrimonial - educação, memórias e identidades. Caderno Temático 3. 1. ed. João Pessoa: Iphan, 2013. v. 3. p. 27-31.

CHAGAS, Mario de Souza. Patrimônio é o caminho das formigas... In: Anais do Museu Histórico Nacional, Rio de Janeiro, v.47, p.175-196, 2015.

CHUVA, Márcia. Preservação do Patrimônio Cultural no Brasil: Uma Perspectiva Histórica, Ética e Política. In: Patrimônio Cultural Políticas e Perspectivas de Preservação no Brasil. Organizadores: Márcia Chuva e Antonio Gilberto Ramos Nogueira. Rio de Janeiro: Mauad X: FAPERJ, 2012. p. 67-78

GOMES, Marta Taets. Patrimônios de Duque de Caxias: história e memória no Museu Vivo do São Bento. Orientadora Maria Aparecida da Silva Cabral. 2016. 97f. Dissertação (Mestrado Profissional em Rede Nacional - PROFHISTORIA) -Programa de Pós-Graduação em História, Universidade do Estado do Rio de Janeiro, São Gonçalo, 2016.

INSTITUTO DO PATRIMÔNIO HISTÓRICO E ARTÍSTICO (IPHAN). Educação Patrimonial: histórico, conceitos e processos. Texto de Sônia Rampim Florêncio. Brasília, DF: Iphan/DAF/ Cogedip/Ceduc, 2014.
NAJJAR, Jorge. Educação Patrimonial e Identidade: Algumas questões em debate. In: CARNEIRO, Waldeck; CHAVES, Iduína M.; LINHARES, Célia; COSTA, Valdelúcia A. (Org.) Movimentos Instituintes em educação: políticas e práticas. Niterói: Intertexto, 2010. p. 141-153 (Coleção Educação e Vida Nacional n. 1).

NOGUEIRA, Risonete. Entrevista concedida a Tatiane Oliveira de Assumpção Cordeiro. Transcrição manuscrita. out. de 2018.

NORA, Pierre. Entre Memória e História: a problemática dos lugares. Projeto História, São Paulo, n. 10, p. 7-28, dez. 1993.

NORA, Pierre. Memória: da liberdade à tirania. Revista Musas, n. 4, p. 6-10, 2009.

OLIVEIRA, Jacqueline de. Entrevista concedida a Tatiane Oliveira de Assumpção Cordeiro. Transcrição manuscrita. out. de 2018.

SOCORRO, Maria do. Entrevista concedida a Tatiane Oliveira de Assumpção Cordeiro. Transcrição manuscrita. out. de 2018.

SOUZA, Marlúcia de. Entrevista concedida a Tatiane Oliveira de Assumpção Cordeiro. Transcrição manuscrita. out. de 2018.

VARINE, Hugues. As raízes do futuro: o patrimônio a serviço do desenvolvimento local. Tradução: Maria de Lourdes Parreiras Horta. $1^{\text {a }}$ reimp. Porto Alegre: Medianiz, 2013.

VIANA, Uhelinton Fonseca. Patrimônio e Educação: desafios para o processo de ensinoaprendizagem. Orientadora: Eda Maria de Oliveira Henriques. 2009. 180 f. Dissertação (Mestrado em Educação) - Programa de Pós-Graduação em Educação, Universidade Federal Fluminense, Niterói, 2009.

VIANA, Uhelinton Fonseca. A educação com o patrimônio e a educação como patrimônio: uma política na formação de professores. Orientadora Carmen Lúcia Vidal Pérez. 2016. 450f. Tese (Doutorado em Educação) -Programa de PósGraduação em Educação, Universidade Federal Fluminense, Niterói, 2016. 